\title{
Can NFL Combine Results be Used to Estimate NFL Defensive Players Longevity?
}

\section{()(1) $\odot \Theta$}

\author{
Authors \\ Jordan Riley Pollock ${ }^{1}$ D, Matthew K. Doan ${ }^{1}$, Walker L. Asprey ${ }^{1}$, Donald L. Dulle², M. Lane Moore ${ }^{1}$, Justin L. Makovicka², \\ Jeffrey D. Hassebrock², Brittany M. Foley ${ }^{1}$, Anikar Chhabra²
}

\author{
Affiliations \\ 1 School of Medicine, Mayo Clinic Arizona, Scottsdale, \\ United States \\ 2 Department of Orthopedic Surgery, Mayo Clinic Arizona, \\ Phoenix, United States
}

Key words

sports medicine, NFL, football, NFL combine, NFL combine results, National Football League

received 05.01 .2021

Revised 02.04.2021

accepted 15.04.2021

\section{Bibliography}

Sports Medicine International Open 2021; 5: E59-E64

DOI 10.1055/a-1485-0031

ISSN 2367-1890

2021. The Author(s).

This is an open access article published by Thieme under the terms of the Creative Commons Attribution-NonDerivative-NonCommercial-License, permitting copying and reproduction so long as the original work is given appropriate credit. Contents may not be used for commercial purposes, or adapted, remixed, transformed or built upon. (https://creativecommons. org/licenses/by-nc-nd/4.0/)

Georg Thieme Verlag KG, Rüdigerstraße 14,

70469 Stuttgart, Germany

\section{Correspondence}

Jordan Riley Pollock

Mayo Clinic Arizona, School of Medicine, 13400 E Shea Blvd., 85259-5499 Scottsdale

United States

Tel.: 2067950144

pollock.jordan@mayo.edu

\section{ABSTRACT}

The National Football League Scouting Combine is an annual event held to evaluate football players. The results of the combine are used to identify talent and player potential. Our study aims to examine the relationship between combine drill performance (e.g., speed, power, agility, explosiveness) and career longevity. We performed a retrospective review of The $\mathrm{Na}$ tional Football League combine test results for all defensive players from 2005-2015 to determine the association of each player's combine test results with career longevity. The position that had the most significant associations for 1 -year status was linebackers, with weight, 10-yard dash, 20-yard dash, 40yard dash, broad jump, 3-cone drill, and shuttle being significantly associated with 1-year roster status. The position that had the most significant associations for 5 -year status was cornerbacks, with weight, 10-yard dash, 20-yard dash, 40-yard dash, 3-cone drill, and shuttle being significantly associated with 1 -year roster status. The least number of significant associations was found for safeties, with no drill being associated with 1-year roster status and only height and shuttle time significantly associated with 5-year career longevity. Our study demonstrates the utility of the combine results to help estimate the career longevity of NFL defensive players.

\section{Introduction}

The National Football League (NFL) Scouting Combine is an annual event where hundreds of college football players across the nation gather for physical, medical, and psychological evaluation [1, 2]. The combine includes substantial medical testing, with each player receiving an orthopedic grade that estimates a player's injury risk [3]. For example, a study examining the combine from 1987 to 2000 showed players receiving a high orthopedic grade having a mean career length of 42 games, players with a low orthopedic grade playing 34 games, and players with a failed orthopedic grade playing 19 games [4]. Other studies have shown how injury prior to the combine, among other characteristics, can help estimate ca- 
reer longevity and how a player's draft status may be negatively affected [4-8].

In addition to medical testing and orthopedic grade, the standardized physical testing performed at the combine are objective measures that provide a potential focus for study [9]. Furthermore, the drills players perform are related to potential injury-reducing traits, which are physical traits thought to reduce risk of injury, such as ankle flexibility, proprioceptive ability, proper biomechanics, and jump strength [10-13]. These are important factors to consider when assessing a player's risk for injury that are not directly measured in the orthopedic grading. Performance of athletes in the standardized physical testing of the NFL combine could offer insight into the performance and health of players in their future career [14].

Many previous studies have been performed that have sought to find a link between prior orthopedic injury or NFL combine orthopedic testing results and career outcomes [3,15-21]. For example one such study found that certain injuries, such as cervical spine injury, rotator cuff repair, or navicular injury, led to decreased career length when compared to a control group [3]. However, our study aims to determine the relationship between combine physical testing and drill performance and career longevity. A study recently established the relationship between combine physical performance and career longevity for offensive NFL players, but information regarding defensive players is scarce [7]. To our knowledge, our study is the first to perform an in-depth analysis of original and normalized combine drill performance and career longevity for defensive NFL players. We hypothesize better performance in the NFL combine will have a significant association with career length for all defensive positions.

\section{Methods}

Due to the public nature of the NFL combine database and the deidentification of our results in this study, this study received institutional review board (IRB) approval and deemed exempt from our institution's approval board. Our analysis meets the ethical stand- ards of the Sports Medicine International Open journal [22]. Analysis was completed of all players who competed in the NFL combine from 2005 through 2015. Combine results were retrospectively collected from NFLdraftscout.com, a public website that provides historical combine results. Results from each drill that a player had performed at the combine were recorded. These included height in inches (non-modifiable); weight; BMI (body mass index); 10-, 20-, and 40-yard dash times; bench press repetitions; vertical jump height in inches; broad jump distance in inches; short shuttle and 3-cone times. The significance of a player's performance on a given combine test can be evaluated by understanding what skills and traits each drill tests [ $\vee$ Table 1]. Career length data were collected using ProFootballReference.com and cross-referenced using NFL.com team websites from all NFL seasons between 2005-2017.

The analysis included each player's combine results and a ratioscaled normalization of each player's combine results by position. Normalizing refers to adjusting a player's performance measures by his body size relative to those that he is being compared against, such as a position group. A ratio scaled normalization, which divides the player performance numbers by their body mass index, was used for this study. First, an average BMI was taken for each position. Next, each player's BMI was divided by the average for his position in their respective combine year, so that heavier players would have a higher relative density score. Lastly, combine scores were normalized for each player by dividing by their scaled BMI, which gave a normalized result for each test.

The influence of each performance metric on whether or not a player was on a roster after the combine was evaluated individually using Student's t-test. Analyses were conducted in R 3.4.2. All hypotheses tested were two-sided with $\mathrm{P}<0.05$ considered statistically significant. There was no adjustment for multiple testing.

Our study initially included 10 -year roster status in our statistical analysis. However, due to the lack of NFL players who play ten seasons and subsequent lack of significance, we excluded the 10year roster status from our study.

- Table 1 Combine drill descriptions.

\begin{tabular}{|c|c|c|}
\hline Test & How Test is Performed & Significance of Test \\
\hline Sprints & $\begin{array}{l}\text { Performed by running } 40 \text { yards from a 3-point stance. Split times recorded at } 20 \text { and } \\
10 \text { yards serve as the measurements for the } 20 \text { - and } 10 \text {-yard dashes, respectively }\end{array}$ & $\begin{array}{l}\text { - Speed } \\
\text { - Explosiveness } \\
\text { - First-step quickness }\end{array}$ \\
\hline 3-Cone Drill & Performed by a player running around 3 cones that are placed in the shape of an "L." & $\begin{array}{l}\text { - Speed } \\
\text { - Power } \\
\text { - Flexibility } \\
\text { - Agility }\end{array}$ \\
\hline 20-yard Shuttle & $\begin{array}{l}\text { Requires a player to run } 5 \text { yards, turn, run back in the opposite direction for } 10 \text { yards, } \\
\text { and then turn again to run } 5 \text { yards back to the starting point. }\end{array}$ & $\begin{array}{l}\text { - Agility } \\
\text { - Acceleration } \\
\text { - Power } \\
\text { - Lateral quickness } \\
\text { - Coordination }\end{array}$ \\
\hline Vertical Jump & $\begin{array}{l}\text { Measured using a Vertec device, which the player stands underneath, extends their arm to } \\
\text { mark their maximum extension, and then jumps to hit markers on the Vertec. The } \\
\text { measured difference between standing reach and jumping reach gives a final vertical jump. }\end{array}$ & $\begin{array}{l}\text { - Power } \\
\text { - Explosiveness }\end{array}$ \\
\hline Broad Jump & Requires the player to jump outward from a two-foot standing position & $\begin{array}{l}\text { - Lower body strength } \\
\text { - Explosiveness }\end{array}$ \\
\hline Bench Press & Players bench press 225 pounds as many times as they can without re-racking the bar & $\begin{array}{l}\text { - Upper body strength } \\
\text { - Endurance }\end{array}$ \\
\hline
\end{tabular}




\section{Results}

A total of 339 cornerbacks, 356 linebackers, 185 safeties, and 278 inside defensive linemen were identified from the NFLdraftscout. com database between 2005-2015. Of these players, 60 cornerbacks, 61 linebackers, 32 safeties, and 46 inside defensive linemen completed ten NFL seasons and the entire list of combine drills. The 20-yard dash was not completed by inside defensive linemen and was thus not included in this study for this specific position.

\section{All defensive positions}

A summary of significant results for each position are found in - Table 2.

\section{Physical characteristics (height and weight)}

We found no association between height and 1-year roster status. Notwithstanding, we found an inverse relationship between height and 5-year roster status for safeties, with shorter safeties being more likely to be on a 5-year roster (72.19 inches vs. 72.83 inches).

We found that higher weight was significantly associated with 1 -year status for linebackers (241.15 vs. 238.25) and inside defensive lineman (306.86 pounds vs. 301.21 pounds). We found a sig-

- Table 2 Significant combine results by year and position.

\begin{tabular}{|l|l|l|}
\hline Position & 1 Year & 5 Year \\
\hline Cornerback & 20-yard dash & Weight \\
& 40 -yard dash & 10 -yard dash \\
& Broad Jump & 20-yard dash \\
& & 40 -yard dash \\
& & 3 -cone drill \\
& & Shuttle \\
\hline Linebacker & Weight & 10 -yard dash \\
& 10 -yard dash & 20 -yard dash \\
& 20 -yard dash & 40 -yard dash \\
& 40 -yard dash & 3 -cone drill \\
& Broad jump3-cone-drill & Shuttle \\
& Shuttle & \\
\hline Safety & & Height \\
& & Shuttle \\
\hline Inside & Weight & 40 -yard dash \\
Defensive & 10 -yard dash & Shuttle \\
Lineman & Shuttle & \\
\hline
\end{tabular}

nificant association between weight and cornerback 5-year status (194.20 pounds vs. 191.20 pounds) ( Table 3).

\section{Speed and first-step quickness (10-, 20-, 40-yard dash)}

We found the 10-yard dash was significantly associated with 1-year roster status for linebackers ( 1.61 seconds vs. 1.65 seconds) and inside defensive lineman (1.74 seconds vs. 1.78 seconds). The 10-yard dash was also significantly associated with 5 -year roster status for cornerbacks ( 1.52 seconds vs. 1.56 seconds) and linebackers ( 1.60 seconds vs. 1.62 seconds).

The 20-yard dash was significantly associated with 1-year status for cornerbacks ( 2.57 seconds vs. 2.63 seconds) and linebackers ( 2.69 seconds vs. 2.75 seconds). The 20 -yard dash was also significantly associated with 5 -year roster status for cornerbacks ( 2.55 seconds vs. 2.63 seconds) and linebackers ( 2.69 seconds vs. 2.74 seconds).

The 40-yard dash was significantly associated with 1-year status for cornerbacks ( 4.47 seconds vs. 4.55 seconds) and linebackers (4.68 seconds vs. 4.82 seconds). The 40 -yard dash was also significantly associated with 5-year roster status for cornerbacks (4.42 seconds, 4.54 seconds), linebackers (4.66 seconds vs. 4.75 seconds), and inside defensive lineman ( 5.03 vs. 5.13 seconds) ( Table 4).

\section{Explosiveness and power (broad jump)}

The broad jump was significantly associated with 1-year status for cornerbacks (122.71 inches vs. 118.98 inches) and linebackers (116.95 inches vs. 114.52 inches) but was not associated with 5-year roster status for any defensive position ( $\triangleright$ Table 5 ).

\section{Agility (3-cone drill, shuttle)}

The 3-cone drill was significantly associated with 1 -year roster status for linebackers ( 7.13 seconds vs. 7.32 seconds), 5-year roster status for linebackers (7.11 seconds vs. 7.20 seconds), and 5-year roster status for cornerbacks ( 6.89 seconds vs. 7.00 seconds)

The shuttle drill was significantly associated with 1-year roster status for linebackers ( 4.29 seconds vs. 4.41 seconds) and inside defensive lineman ( 4.65 seconds vs. 4.74 seconds). The shuttle drill was also significantly associated with 5 -year roster status for cornerbacks (4.14 vs. 4.23 seconds), linebackers ( 4.27 vs. 4.34 sec-

- Table 3 Average combine results for physical characteristics (height and weight) of defensive positions compared to roster status.

\begin{tabular}{|c|c|c|c|c|c|}
\hline \multicolumn{6}{|c|}{ Physical Characteristics } \\
\hline \multirow{2}{*}{\multicolumn{2}{|c|}{ Position }} & \multicolumn{2}{|c|}{1 Year } & \multicolumn{2}{|c|}{5 Year } \\
\hline & & Yes & No & Yes & No \\
\hline \multirow{2}{*}{ Cornerback } & Height Mean (sd) & $71.24(1.47)$ & $70.90(1.72)$ & $71.31(1.56)$ & $71.13(1.45)$ \\
\hline & Weight Mean (sd) & $193.04(8.54)$ & $192.12(9.09)$ & $194.20 *(9.44)$ & $191.20(8.02)$ \\
\hline \multirow{2}{*}{ Linebacker } & Height Mean (sd) & $73.59(1.28)$ & $73.43(1.55)$ & $73.59(1.21)$ & $73.40(1.41)$ \\
\hline & Weight Mean (sd) & $241.15 *(8.68)$ & $238.25(9.13)$ & $240.46(7.84)$ & $240.00(9.57)$ \\
\hline \multirow{2}{*}{ Safety } & Height Mean (sd) & $72.28(1.44)$ & $72.83(1.35)$ & $72.19 *(1.46)$ & $72.83(1.51)$ \\
\hline & Weight Mean (sd) & $208.36(9.03)$ & $208.80(9.49)$ & $208.68(9.69)$ & $208.58(9.40)$ \\
\hline \multirow{2}{*}{$\begin{array}{l}\text { Inside Defensive } \\
\text { Lineman }\end{array}$} & Height Mean (sd) & $75.06(1.45)$ & $74.90(1.47)$ & $75.05(1.32)$ & $74.85(1.41)$ \\
\hline & Weight Mean (sd) & $306.86 *(16.93)$ & 301.21 (15.79) & $305.63(15.93)$ & $303.39(15.49)$ \\
\hline
\end{tabular}


- Table 4 Average combine results for speed and first-step quickness (10-, 20-, 40-yard dash) of defensive positions compared to roster status.

\begin{tabular}{|c|c|c|c|c|c|}
\hline \multicolumn{6}{|c|}{ Speed and First-step Quickness } \\
\hline \multirow{2}{*}{\multicolumn{2}{|c|}{ Position }} & \multicolumn{2}{|c|}{1 Year } & \multicolumn{2}{|c|}{5 year } \\
\hline & & Yes & No & Yes & No \\
\hline \multirow{3}{*}{ Cornerback } & 10-yard dash Mean (sd) & $1.55(0.08)$ & $1.57(0.08)$ & $1.52 *(0.08)$ & $1.56(0.08)$ \\
\hline & 20-yard dash Mean (sd) & $2.57 *(0.11)$ & $2.63(0.12)$ & $2.55 *(0.11)$ & $2.63(0.12)$ \\
\hline & 40-yard dash Mean (sd) & $4.47 *(0.18)$ & $4.55(0.21)$ & $4.42 *(0.17)$ & $4.54(0.19)$ \\
\hline \multirow{3}{*}{ Linebacker } & 10-yard dash Mean (sd) & $1.61 *(0.07)$ & $1.65(0.07)$ & $1.60 *(0.07)$ & $1.62(0.08)$ \\
\hline & 20-yard dash Mean (sd) & $2.69 *(0.10)$ & $2.75(0.18)$ & $2.69 *(0.10)$ & $2.74(0.12)$ \\
\hline & 40-yard dash Mean (sd) & $4.68 *(0.17)$ & $4.82(0.17)$ & $4.66 *(0.16)$ & $4.75(0.18)$ \\
\hline \multirow{3}{*}{ Safety } & 10-yard dash Mean (sd) & $1.56(0.08)$ & $1.57(0.07)$ & $1.54(0.09)$ & $1.57(0.08)$ \\
\hline & 20-yard dash Mean (sd) & $2.61(0.12)$ & $2.62(0.12)$ & $2.61(0.14)$ & $2.64(0.11)$ \\
\hline & 40-yard dash Mean (sd) & $4.54(0.20)$ & $4.55(0.20)$ & $4.52(0.21)$ & $4.58(0.20)$ \\
\hline \multirow{2}{*}{$\begin{array}{l}\text { Inside Defensive } \\
\text { Lineman }\end{array}$} & 10-yard dash Mean (sd) & $1.74 *(0.10)$ & $1.78(0.10)$ & $1.72(0.1)$ & $1.75(0.10)$ \\
\hline & 40-yard dash Mean (sd) & $5.06 *(0.25)$ & $5.18(0.26)$ & $5.03 *(0.24)$ & $5.13(0.26)$ \\
\hline
\end{tabular}

- Table 5 Average combine results for explosiveness and power (broad jump) of defensive positions compared to roster status.

\begin{tabular}{|c|c|c|c|c|c|}
\hline \multicolumn{6}{|c|}{ Explosiveness and Power } \\
\hline \multirow{2}{*}{\multicolumn{2}{|c|}{ Position }} & \multicolumn{2}{|c|}{1 Year } & \multicolumn{2}{|c|}{5 Year } \\
\hline & & Yes & No & Yes & No \\
\hline Cornerback & Broad Jump Mean (sd) & $122.71 *(7.53)$ & $118.98(7.96)$ & $122.28(7.72)$ & $121.60(8.13)$ \\
\hline Linebacker & Broad Jump Mean (sd) & $116.95 *(7.67)$ & $114.52(8.34)$ & $116.41(7.67)$ & $114.97(7.86)$ \\
\hline Safety & Broad Jump Mean (sd) & $120.74(7.43)$ & $121.88(10.05)$ & $120.82(7.68)$ & $120.08(7.74)$ \\
\hline $\begin{array}{l}\text { Inside Defensive } \\
\text { Lineman }\end{array}$ & Broad Jump Mean (sd) & $105.72(10.69)$ & $107.47(11.36)$ & $106.81(10.13)$ & $106.14(10.96)$ \\
\hline
\end{tabular}

- Table 6 Average combine results for agility (3-cone drill and shuttle) of defensive positions compared to roster status.

\begin{tabular}{|c|c|c|c|c|c|}
\hline \multicolumn{6}{|c|}{ Agility } \\
\hline \multirow{2}{*}{\multicolumn{2}{|c|}{ Position }} & \multicolumn{2}{|c|}{1 Year } & \multicolumn{2}{|c|}{5 Year } \\
\hline & & Yes & No & Yes & No \\
\hline \multirow[t]{2}{*}{ Cornerback } & 3-Cone Drill Mean (sd) & $6.93(0.32)$ & $7.02(0.37)$ & $6.89 *(0.34)$ & $7.00(0.33)$ \\
\hline & Shuttle Mean (sd) & $4.18(0.22)$ & $4.23(0.25)$ & $4.14 *(0.22)$ & $4.23(0.21)$ \\
\hline \multirow[t]{2}{*}{ Linebacker } & 3-Cone Drill Mean (sd) & $7.13 *(0.28)$ & $7.32(0.28)$ & $7.11 *(0.27)$ & $7.20(0.31)$ \\
\hline & Shuttle Mean (sd) & $4.29 *(0.19)$ & $4.41(0.21)$ & $4.27 *(0.18)$ & $4.34(0.21)$ \\
\hline \multirow[t]{2}{*}{ Safety } & 3-Cone Drill Mean (sd) & $6.96(0.31)$ & $7.04(0.33)$ & $6.91(0.37)$ & $7.04(0.27)$ \\
\hline & Shuttle Mean (sd) & $4.21(0.21)$ & $4.26(0.12)$ & $4.16 *(0.24)$ & $4.26(0.18)$ \\
\hline \multirow{2}{*}{$\begin{array}{l}\text { Inside Defensive } \\
\text { Lineman }\end{array}$} & 3-Cone Drill Mean (sd) & $7.68(0.38)$ & $7.73(0.35)$ & $7.65(0.38)$ & $7.76(0.37)$ \\
\hline & Shuttle Mean (sd) & $4.65 *(0.25)$ & $4.74(0.25)$ & $4.62 *(0.22)$ & $4.71(0.26)$ \\
\hline
\end{tabular}

onds), safety (4.16 vs 4.26 seconds), and inner defensive lineman (4.62 seconds vs. 4.71 seconds) ( $\triangleright$ Table 6 ).

\section{Discussion}

The standardized physical testing performed by players in the NFL combine is utilized by NFL coaches, teams, and team physicians to measure a player's athleticism and future potential [14]. Our study found certain combine drills correlated with longer NFL careers for each position for defensive players. Out of all the combine tests, the 20-yard dash results had the highest number of significant associations with 1 -year roster status, with 3 of 4 defensive positions yielding significant results. We found a significant association with the shuttle results and 5-year roster status for all 4 defensive positions. This was closely followed by the 40 -yard dash results, which was significantly associated with 5 -year roster status for 3 of 4 positions. The combine results that were not significantly associated with 1-year roster status and 5-year roster status were height and 
weight, respectively. Whereas other studies have investigated the use of various combine tests to estimate NFL career success or propensity for injury, our study is the first to perform an in-depth analysis examining the relationship between standardized physical testing in the NFL combine and career longevity.

Explosiveness and power is measured in the NFL combine through the vertical and broad jumps [23]. Our study shows a significant association between broad jump and 1-year roster status for cornerbacks and linebackers. However, there was no significant association between the broad jump and 5-year status for any of the studied defensive positions.

Agility is measured through the 3-cone drill and shuttle. The shuttle test had the most significant findings among the two tests, with faster times significantly associated with 1-year roster status for linebackers and inside defensive lineman and significantly associated with 5-year roster status for all positions - cornerbacks, linebackers, safeties, and inside defensive lineman. The 3-cone drill speed was significantly associated with 1 -year roster status among linebackers and 5-year status among cornerbacks and linebackers.

Short distance speed and first-step quickness are extrapolated from the 10-, 20- and 40-yard dashes. Faster 10-, 20-, and 40-yard dash times were correlated with increased likelihood of 1-year and 5-year roster status among linebackers, indicating a significant association between all linebacker dash times and career longevity. Among a variety of significant findings, the 40 -yard dash was the most valuable test for cornerbacks and inner defensive lineman, with an increased likelihood of 1-year and 5-year roster status for both positions. No significant association was found with 10-, 20-, and 40-yard dashes among safeties for 1 -year or 5 -year roster status, however, this was likely due to the small sample size of safeties and should be studied further.

A previous study by Berri et al. [24] reported height as having a significant association with career length for certain positions, such as quarterbacks, however our results demonstrated height was inversely correlated with career longevity for safeties, with each 0.25 inch increase in height correlating with a decrease of $7.2 \%$ chance of being on the 5-year roster. Height was not significantly correlated with any defensive position. Inside defensive lineman and linebackers with higher weights had significantly increased chances of being on the 1-year roster; however weight had no significant effect on 5-year roster status. In contrast, we found a significant association with weight and 5-year roster status for cornerbacks, indicating increased weight among cornerbacks leads to longer career longevity.

A limitation to our study is the use of online NFL combine results, which are dependent on accurate data collection and recording. Despite this limitation, the NFL combine results are widely used in scientific study. Another limitation of our study is the use of normalized data, which we calculated without allometric adjustments. Although BMI can be less useful in individuals at the extremes of body mass, such as professional athletes, we attempted to account for this by normalizing the data and comparing individuals by position group using a ratio-scaled normalization. A ratio-scaled normalization refers to normalizing BMI by dividing weight over group $\mathrm{BMI}$, and allosteric normalization uses specific exponents tailored to the group that is being studied to derive its normalization. By using a scaled BMI approach in interpreting the data, we feel it al- lowed for the most accurate comparison in the absence of a consistent exponent for allometric adjustments in football players. Allometric adjustments are intended to provide a more accurate normalization of athletic drill performance by assigning an exponent value to describe body shape and size rather than simply BMI. Therefore, allometric adjustments could be useful if an accurate exponent for American football athletes is developed. Our study also attempts to determine the relationship of combine results and career longevity for a dynamic sport in which athletes experience an extreme variance of situations, playing conditions, and more. Although our results are useful and informative, caution must be taken when applying these results to individual athletes. Of course, athletes with excellent results could experience catastrophic injuries and shortened careers, and athletes with below-average results could have lengthy careers. Further, injury mechanism was not accounted for when considering career length variance,

The NFL combine is used to evaluate football players. Although the combine is useful to help NFL teams gather medical histories, perform physical exams, and perform athletic tests to filter through and recruit the most promising players, our study demonstrates the utility of the combine physical testing results for estimating career longevity for defensive players. This study can be used by NFL teams, team physicians, and other healthcare professionals to assist in the assessment and treatment of NFL defensive players. Future studies should examine whether the NFL combine results could be used in other areas of sports medicine, such as injury prevention.

\section{Conflict of Interest}

$A C$ is a consultant and speaker's bureau member for Arthex. AC is a consultant for Zimmer Biomet. AC received an educational grant from Stryker. None of these present conflicts of interest for this work.

\section{References}

[1] 2020 NFL Combine - NFL Network | NFL.com. Available from: https:// www.nfl.com/network/events/nfl-combine. Accessed: 27 September 2020

[2] National Scouting Combine | NFL Football Operations. Available from: https://operations.nfl.com/the-players/getting-into-the-game/ national-scouting-combine. Accessed: 6 October 2020

[3] Wang D, Weiss LJ, Abrams M et al. Athletes with musculoskeletal injuries identified at the NFL Scouting Combine and prediction of outcomes in the NFL: A systematic review. Orthop J Sports Med 2018; 6. doi:10.1177/2325967118813083

[4] Brophy RH, Chehab EL, Barnes RP et al. predictive value of orthopedic evaluation and injury history at the NFL combine. Med Sci Sports Exerc 2008; 40: 1368-1372. doi:10.1249/MSS.0b013e31816f1c28

[5] Brophy RH, Lyman S, Chehab EL et al. Predictive value of prior injury on career in professional American football is affected by player position. Am J Sports Med 2009; 37: 768-775. doi:10.1177/0363546508329542

[6] Brophy RH, Barnes R, Rodeo SA et al. Prevalence of musculoskeletal disorders at the NFL Combine-trends from 1987 to 2000. Med Sci Sports Exerc 2007; 39: 22-27. doi:10.1249/01. mss.0000241637.52231.18 
[7] Asprey WL, Foley BM, Makovicka JL et al. A 10-year evaluation of the NFL combine. Do combine results correlate with career longevity for NFL offensive players? Phys Ther Rehabil 2020; 7: 8. doi:10.7243/2055-2386-7-8

[8] Mulholland J, Jensen ST. Predicting the draft and career success of tight ends in the National Football League. J Quant Anal Sports 2014; 10: 381-396. doi:10.1515/jqas-2013-0134

[9] NFL Draft Combine Testing. Available from: https://www.topendsports.com/sport/gridiron/nfl-draft.htm. Accessed: 5 October 2020

[10] Murphy DF, Connolly DAJ, Beynnon BD. Risk factors for lower extremity injury: a review of the literature. Br J Sports Med 2003; 37: 13-29. doi:10.1136/bjsm.27.1.13

[11] Gómez-Piqueras P, González-Víllora S, Sainz de Baranda Andújar M, del $P$ et al. Functional assessment and injury risk in a professional soccer team. Sports 2017; 5: 9. doi:10.3390/sports5010009

[12] Riva D, Bianchi R, Rocca F et al. Proprioceptive training and injury prevention in a professional men's basketball team: A six-year prospective study. J Strength Cond Res 2016; 30: 461-475. doi:10.1519/JSC.0000000000001097

[13] Whiting W. Biomechanics of common musculoskeletal injuries in American football. Strength Cond J 2015; 37: 79-87

[14] Kuzmits FE, Adams AJ. The NFL Combine: Does it predict performance in the National Football League? J Strength Cond Res 2008; 22: 1721-1727. doi:10.1519/JSC.0b013e318185f09d

[15] Beaulieu-Jones BR, Rossy WH, Sanchez G et al. Epidemiology of injuries identified at the NFL Scouting Combine and their impact on performance in the National Football League: Evaluation of 2203 athletes From 2009 to 2015. Orthop J Sports Med 2017; 5: 2325967117708744. doi:10.1177/2325967117708744

[16] Chahla J, Cinque ME, Godin JA et al. Meniscectomy and resultant articular cartilage lesions of the knee among prospective National Football League players: an imaging and performance analysis. Am J Sports Med 2018; 46: 200-207. doi:10.1177/0363546517737991
[17] Chahla J, Kennedy NI, Cinque ME et al. Posterolateral corner injuries of the knee at the National Football League Combine: an imaging and outcomes analysis. Arthroscopy 2018; 34: 687-692. doi:10.1016/j. arthro.2017.08.303

[18] McHale KJ, Vopat BG, Beaulieu-Jones BR et al. Epidemiology and outcomes of Lisfranc injuries identified at the National Football League Scouting Combine. Am J Sports Med 2017; 45: 1901-1908. doi: $10.1177 / 0363546517697297$

[19] Murphy CP, Frangiamore SJ, Mannava S et al. Effect of anterior glenoid labral tears and glenoid bone loss at the NFL combine on future NFL performance. Orthop J Sports Med 2018; 6: 2325967118784884. doi: $10.1177 / 2325967118784884$

[20] Provencher MT, Bradley JP, Chahla J et al. A history of anterior cruciate ligament reconstruction at the National Football League combine results in inferior early National Football League career participation. Arthroscopy 2018; 34: 2446-2453. doi:10.1016/j.arthro.2018.03.018

[21] Vopat B, Beaulieu-Jones BR, Waryasz G et al. Epidemiology of navicular injury at the NFL combine and their impact on an athlete's prospective NFL career. Orthop J Sports Med 2017; 5: 2325967117723285. doi:10.1177/2325967117723285

[22] Harriss D], MacSween A, Atkinson G. Ethical standards in sport and exercise science research: 2020 update. Int J Sports Med 2019; 40: 813-817. doi:10.1055/a-1015-3123

[23] Krishnan A, Sharma D, Bhatt M et al. Comparison between standing broad jump test and Wingate test for assessing lower limb anaerobic power in elite sportsmen. Med ] Armed Forces India 2017; 73 : 140-145. doi:10.1016/j.mjafi.2016.11.003

[24] Berri DJ, Simmons R. Catching a draft: on the process of selecting quarterbacks in the National Football League amateur draft. J Product Anal 2011; 35: 37-49. doi:10.1007/s11123-009-0154-6 